\title{
PERANCANGAN CERITA WEBTOON MENGENAI BUDAYA PALANG PINTU
}

\author{
Arief Triadi ${ }^{1}$, Yanuar Rahman ${ }^{2}$ \\ 1,2Desain Komunikasi Visual, Fakultas Industri Kreatif, Universitas Telkom \\ Terusan Buah Batu Bandung 40257
}

\begin{abstract}
Abstrak: Budaya Palang Pintu merupakan salah satu bagian pada prosesi pernikahan Adat Betawi yang melibatkan kesenian silat dan berbalas pantun. Saat ini budaya tersebut menjadi salah satu budaya yang berusaha dilestarikan oleh Pemerintah Kota Tangerang Selatan. Berkaitan dengan perkembangan zaman, percepatan informasi, serta media alternatif yang kerap digunakan oleh remaja, beberapa saluran alternatif seperti webtoon mampu menjadi media dan wadah informasi serta edukasi yang cukup efektif untuk mengakses informasi tentang Budaya Palang Pintu ini. Selain itu dengan menggunakan paparan cerita mengenai Palang Pintu dalam kemasan webtoon, pembaca diharapkan bisa lebih mudah menerima dan menyerap informasi dan edukasi yang tertuang di dalamnya. Metode kualitatif digunakan dalam penelitian ini, pengumpulan data dilakukan melalui studi pustaka, wawancara dan observasi, kemudian data dianalisis menggunakan metode matriks perbandingan. Hasil penelitian menunjukkan bahwa perancangan webtoon bisa turut berperan dalam melestarikan unsur dan nilai budaya tradisional Indonesia, khususnya Budaya Palang Pintu.
\end{abstract}

Kata kunci: Betawi, budaya, palang pintu, webtoon

Abstract: Palang Pintu tradition is one part of the procession during a Betawi wedding ceremony that involves the art of silat and rhymes. Palang Pintu tradition is currently one of the cultures that is sought and maintained by the South Tangerang City Government. Concerned with the development and acceleration of the technology information, as well as alternative media often used by teenagers, some alternative channels such as webtoon can be a medium and container of information and education that is effective enough to obtain information about this tradition. In addition, by using the exposure of the story about the Palang Pintu tradition in the form of webtoon, readers who are teenagers are expected to more easily receive and absorb the information and education contained in it. Qualitative method is used in this research, data collection is done through literature study, interview and observation, then the data is analyzed by using comparison matrix method. The result is that webtoon can play a role in preserving the elements and cultural values of Indonesia, especially the Palang Pintu Tradition.

Keywords: betawi, culture, palang pintu, webtoon

${ }^{1}$ Mahasiswa Program Studi DKV Telkom University, email: riddifgreen@gmail.com

${ }^{2}$ Dosen Program Studi DKV Telkom University dan juga ilustrator buku anak, email: vidiyan@gmail.com 


\section{PENDAHULUAN}

Sebagai kota hasil pemekaran, Kota Tangerang Selatan memiliki beberapa budaya tradisional yang perlu untuk dipertahankan salah satunya adalah Budaya Palang Pintu. Budaya Palang Pintu merupakan salah satu bagian dalam prosesi pernikahan adat betawi yang melibatkan silat dan pantun dengan iringan alat musik seperti gendang, kecrek, gambang kromong dan lainnya. Namun sayangnya Budaya Palang Pintu ini tidak begitu banyak diketahui orang terutama para generasi muda, karena berdasarkan hasil kuesioner kepada responden usia 17 24 tahun yang berdomisili di Jakarta, Tangerang Selatan dan Bandung sebanyak $57,4 \%$ responden menyatakan tidak mengetahui tentang budaya Palang Pintu. Adapun pembahasan mengenai Budaya Palang Pintu hanya bisa dijumpai di bukubuku anak dan buku mata pelajaran sekolah dasar, yang sejatinya konteksnya kurang sesuai bagi siswa sekolah dasar karena berkisah mengenai prosesi pernikahan.

Seiring dengan hal tersebut perkembangan teknologi informasi dan media komunikasi memunculkan banyak bentuk media-media baru yang menyesuaikan dengan audiens dan segala perangkat teknologi yang ada saat ini. Transformasi media-media analog juga berkembang cepat, salah satunya adalah komik yang mengalami penyesuaian dalam bentuk alternatifnya seperti web comic atau webtoon. Sebagai sebuah media yang dapat disimak oleh banyak pengguna terutama yang berusia 17 hingga 24 tahun, webtoon mampu dijadikan sebagai wadah publikasi, informasi dan edukasi alternatif yang sesuai dengan minat permisanya.

Di Indonesia platform webtoon yang cukup populer diinisiasi oleh perusahaan komunikasi LINE dari Jepang, yang penggunanya baik laki-laki maupun perempuan, semakin hari semakin meningkat. Selain itu media LINE webtoon merupakan media pilihan yang cocok dan potensial karena Indonesia menempati posisi ketiga dengan pengguna LINE terbanyak setelah Jepang dan Thailand, lalu 
diikuti oleh Spanyol dan India (Statista, 2018), data ini juga menggambarkan bahwa proses dan cara untuk mengakses LINE webtoon itu cukup mudah dilakukan.

Akses yang cepat dan mudah ini dapat membantu mengoptimalisasi proses informasi, sosialisasi dan publikasi tentang pembelajaran mengenai Budaya Palang Pintu yang dilakukan melalui webtoon. Konsep penceritaan dan penokohan yang mengangkat unsur dan nilai budaya yang ada diharapkan dapat membuat webtoon ini lebih menarik sehingga informasi dan edukasi tentang Budaya Palang Pintu bisa mudah diterima, diserap, dinikmati dan dipelajari oleh pembaca yang sesuai, dan membuat budaya tradisonal dari Kota Tangerang Selatan ini bisa terus lestari.

\section{KAJIAN TEORI}

Cho (2016) dalam jurnalnya "The Webtoon: A New Form for Graphic Narrative" menjelaskan bahwa webtoon adalah sistem kompleks yang diciptakan melalui dua media yaitu komik dan digital. Diciptakan di Korea Selatan pada tahun 2000 sebagai nama web untuk internet komik. Tidak lama istilah webtoon menjadi standar dalam menyebut internet komik yang dibuat dan dinikmati oleh Korea.

Dari sekian banyak perbedaan, yang paling signifikan mencirikan sebuah webtoon adalah layout yang vertikal. Maksud penggunaan layout vertikal adalah agar pembaca bisa menggunakan scroll wheel pada mouse untuk membacanya. Webtoon juga termasuk transmediality yang diartikan oleh Steinberg (2012) sebagai teknik menyampaikan satu cerita atau pengalaman cerita yang melintasi berbagai bentuk dan format media dalam bentuk digital.

Bisa disimpulkan bahwa webtoon merupakan inovasi kolektif yang memiliki gaya dan sistem yang spesifik. McCloud (2001: 16) menyimpulkan arti komik sebagai gambar yang saling bersanding dan dengan gambar lainnya secara berurutan, yang dimaksudkan untuk menyampaikan informasi dan/ atau untuk 
menghasilkan respon estetika terhadap pembaca. Hampir sama dengan McCloud, menurut Zpalanzani, Ahmad dan Maulana (2006: 14), komik bisa dibilang sebuah media yang dapat disebar secara massal tapi akan mendapatkan respons dari pembacanya secara personal.

Scott McCloud dalam Making Comics menjelaskan ada beberapa hal yang dibutuhkan dalam membuat komik, dalam hal penyusunan cerita dijelaskan bahwa kita sebagai storyteller menginginkan pembaca mengerti apa yang kita sampaikan dan kita ingin pembaca tetap peduli untuk mengikuti cerita kita sampai akhir. Untuk itu ada lima pilihan yang dibutuhkan agar cerita kita jelas dan meyakinkan. Aspek yang pertama adalah pilihan momen. McCloud (2006: 15) menjelaskan ada beberapa tipe transisi panel ke panel yang bisa membuat cerita lebih baik. Sub-aspek pertama adalah Moment to Moment, transisi yang berguna untuk memberikan kesan ketegangan karena perubahan gambar yang tidak banyak dalam transisinya.

Sub-aspek kedua adalah Action to Action yang biasa digunakan untuk melanjutkan alur dengan pace yang baik. Sub-aspek ketiga adalah Subject to Subject, digunakan sebagai transisi dalam percakapan dua atau lebih karakter. Sub-aspek keempat adalah Scene to Scene, digunakan untuk mengkompres cerita kedalam waktu dan lokasi yang terukur. Sub-aspek kelima adalah Aspect to Aspect, berguna untuk memberikan rasa yang kuat atas tempat dan mood. Dan yang terakhir adalah Non Sequitur, termasuk ke dalam experimental comics yang biasa memberikan pesan positif didalam negatif atau sebaliknya dan atau keduanya sekaligus.

Aspek kedua yang dibutuhkan agar cerita kita jelas dan meyakinkan adalah pilihan frame, yang menentukan seberapa detail gambar dalam panel, seberapa jauh gambar guna memperlihatkan ruang dan tempat, menentukan keseimbangan dan potongan, serta menentukan posisi dalam dunia tersebut. Setiap adegan, frame yang cocok digunakan akan berbeda. 
Aspek yang ketiga adalah pilihan gambar, yang menentukan apakah pembaca mengerti arti dari gambar tersebut? Apakah informasi visual yang disampaikan sesuai dengan apa yang kita inginkan? Yang penting adalah clarity atau kejelasan gambar dalam komik, sebagaimana baiknya tujuan dasar panelpanel tersebut.

Aspek keempat adalah pilihan kata. Karena tidak semua informasi bisa diwakilkan oleh gambar, seperti nama dan informasi transisi hanya bisa diwakilkan oleh kata. Yang kelima adalah pilihan alur yang menentukan kejelasan alur baca sehingga tidak membingungkan pembaca. Untuk karakter sendiri menurut Scott, yang dibutuhkan adalah keunikan visual, latar belakang yang lekat dengan manusia, dan mempunyai sifat yang ekspresif. Lalu ekpresi wajah dan bahasa tubuh juga bisa menyampaikan pesan secara emosional. Aspek terakhir adalah membangun dunia yang bertujuan untuk membawa pembaca lebih dalam lagi kedalam cerita. Seperti menggunakan variasi bleed dan menggunakan berbagai macam titik perspektif dan detail pada latar gambar.

\section{METODE PENELITIAN}

Studi pustaka digunakan sebagai acuan dasar untuk merancang webtoon ini sehingga bisa lebih terarah dan jelas, dengan mengacu dari berbagai sumber seperti buku, jurnal, artikel, dan internet yang berkaitan dengan pengertian webtoon, dasar-dasar pembuatan komik, seputar Budaya Palang Pintu, teori Desain Komunikasi Visual, serta informasi pendukung lainnya.

Selain studi pustaka, wawancara juga dilaksanakan untuk mengumpulkan informasi yang tidak didapatkan pada referensi literatur seperti pengalaman dan informasi verbal lainnya. Wawancara dilakukan dengan webtoon artist Vega Mandalika Jhauhary dan Bonny Puspita Tyasti.

Data yang lebih komprehensif juga berusaha didapatkan melalui kuesioner yang disebar melalui media online, ditujukan kepada 100 responden pria dan 
wanita usia 17-24 tahun, berstatus siswa sekolah menengah atas dan mahasiswa berdomisili di kota besar di Indonesia, utamanya Jakarta, Tangerang Selatan dan Bandung, untuk mengetahui minat pasar mengenai webtoon dengan tema terkait, sehingga bisa dijadikan pertimbangan dalam melakukan rancangan. Acuan berikutnya adalah membandingkan tiga karya pilihan yang mewakili objek terkait, yakni webtoon berjudul Mantradeva, Suryaraka dan Wanara. Ketiga karya ini dipilih karena memiliki jumlah pembaca remaja yang cukup signifikan yakni sekitar 20.000 - 200.00 penikmat, mengangkat tema yang memiliki kaitan dengan cerita aksi dan pemaparan cerita dan visual yang popular sesuai dengan karakteristik kesukaan pembaca remaja.

\section{HASIL DAN DISKUSI}

Budaya Palang Pintu adalah salah satu bagian pada prosesi pernikahan Betawi dimana melibatkan adu silat serta pantun yang biasa diiringi oleh rebana, kecrek, gambang kromong dan lainnya. Umumnya, Palang Pintu bertujuan untuk mengetahui keahlian bela diri silat mempelai pria dan keahlian agamanya dengan maksud mengukur kemampuan mempelai pria melindungi calon istri dan keluarganya serta memimpin dalam hal agama.

Acara ini dilakukan sebelum prosesi akad nikah, diawali dengan iring-iringan kedatangan rombongan mempelai pria ke kediaman mempelai wanita dengan diiringi musik rebana. Ketika mempelai pria sudah memasuki wilayah kediaman mempelai wanita, rombongan akan dihentikan oleh "jagoan" dari mempelai wanita yang akan mempertanyakan tujuan dan maksud kedatangannya bersama rombongan. Disinilah proses Palang Pintu itu dinamai, yang berarti menghalangi siapapun yang berusaha memasuki suatu wilayah. 


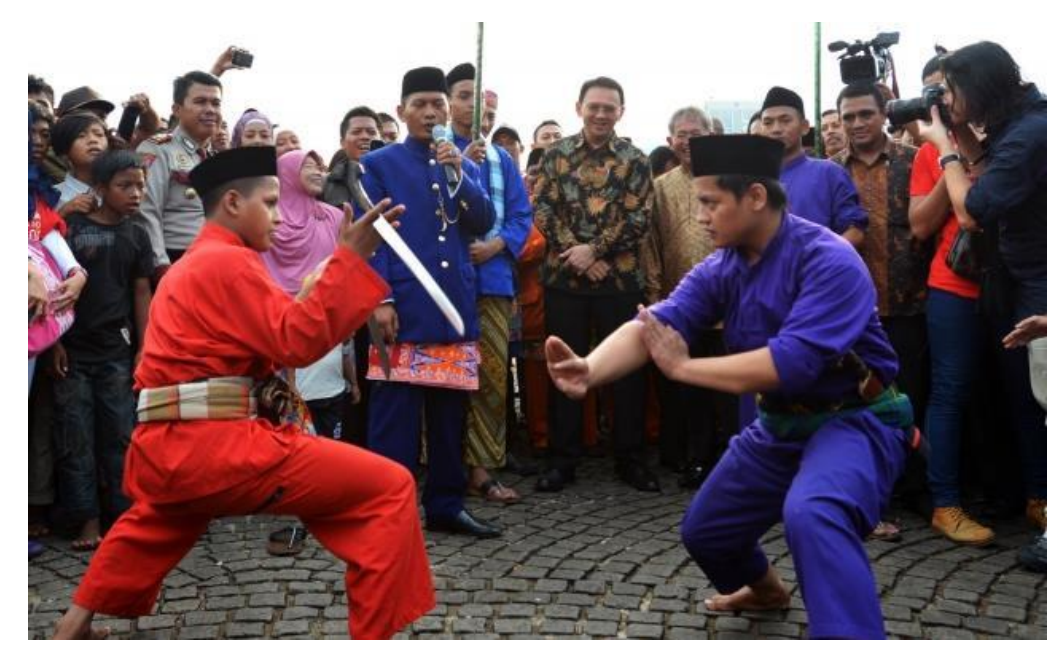

Gambar 1. Tari Palang Pintu

(Sumber: http://merdeka.com, 2017)

"Jagoan Pantun" dari mempelai wanita akan mempertanyakan tujuan dan maksud kedatangan dari rombongan mempelai pria dengan menggunakan pantun. Lalu akan dibalas oleh "Jagoan Pantun" dari mempelai pria dengan menggunakan pantun juga. Dialog dan pantun diawali dengan suasana yang tenang dan sopan, namun seiring berjalannya dialog, pihak mempelai wanita akan mempertanyakan keahlian silat dan agama dari mempelai pria. Disini "Jagoan Silat" yang mewakili mempelai pria akan mengambil alih peran untuk menunjukan keahlian silatnya dengan melawan "Jagoan Silat" dari mempelai wanita. Jagoan Silat dari mempelai pria tentu akan menang melawan Jagoan Silat dari mempelai wanita, karena acara ini bisa dikatakan berupa syarat dan untuk menghibur hadirin undangan yang datang. Setelah rombongan mempelai wanita menerima keahlian silat dan agama dari mempelai pria, prosesi akan dilanjutkan ke akad nikah dan seterusnya.

Berdasarkan hasil analisis data wawancara, terdapat kesimpulan yang bisa dijadikan acuan dalam merancang karya, yakni bahwa webtoon memiliki keuntungan kebebasan dalam halaman karena tidak ada ketentuan pasti dan hal tersebut diserahkan penuh ke webtoon artist, serta webtoon memiliki alur baca 
dari atas ke bawah sehingga fitur scrolling berguna untuk memudahkan pembaca melalui smartphone maupun komputer seperti menggunakan scroll pada mouse.

Kemudian dalam aspek paneling, jarak antar panel bisa disesuaikan berdasarkan adegan yang sedang terjadi, bila terjadi adegan action dan cepat, jarak antar panel bisa diperpendek, dan sebaliknya diperpanjang apabila adegan dramatisasi dan lambat. Jumlah panel dalam satu halaman (2100×10000 pixel) bervariasi, bisa 3-6 panel. Dan untuk jumlah halaman sangat bergantung kepada panjang cerita yang dibuat untuk satu episode, karena tidak bisa terukur pasti. Lalu demi mempertimbangkan kenyamanan pembaca smartphone, ukuran huruf berkisar pada besaran 11 point.

Desain karakter dalam membuat komik yang diutamakan adalah sifat dan latar belakang dahulu, karena fisik bisa mengikuti. Kemudian dalam mengadaptasi elemen budaya diperlukan riset terlebih dahulu seperti membaca referensi, guna mengenal inti budaya tersebut. Tidak lupa dengan memasukkan ide orisinil tanpa merusak dan menghilangkan elemen budaya tersebut.

Dari hasil analisis kuesioner yang telah dilakukan, 57,4\% responden menyatakan tidak mengetahui apa itu Palang Pintu. Namun mereka mau memilih membaca webtoon $(66,2 \%)$ yang berunsur budaya tradisional dibandingkan komik konvensional. Genre yang mereka sukai adalah comedy, slice of life, romance dan fantasy. Untuk hasil analisis perbandingan tiga buah referensi, Suryaraka akan dijadikan acuan dalam penggunaan panel yang kronologis. Serta, Wanara untuk acuan pengambilan perspektif yang baik untuk membangun dunia didalam cerita.

Webtoon juga memiliki kebebasan bila dibandingkan dengan buku komik, seperti bebasnya jumlah halaman. Alur paneling dari atas kebawah dengan memainkan variasi jarak panel sesuai dengan cerita yang terjadi. Font yang digunakan cenderung bertipe sans-serif dengan ukuran minimal 11 point (bergantung pada huruf yang digunakan, sehingga harus disesuaikan). Ilustrasi lebih menarik jika menggunakan outline/ lineart jelas dan paneling yang variatif. 
Webtoon juga memungkinkan jika menggunakan warna yang kompleks. Agar lebih dekat secara emosional dan dapat diterima oleh pembaca cerita bisa dibawakan dengan genre slice of life, dengan sedikit comedy dan romance karena berkaitan dengan objek penelitian. Secara teknis bisa menggunakan transisi action to action agar pembawaan cerita lebih efektif dan efisien. Serta menggunakan transisi subject to subject bila ada percakapan dua karakter atau lebih, dengan divariasikan menggunakan angle yang berbeda-beda. Terakhir visualisasi webtoon dapat menggunakan transisi scene to scene apabila terjadi pergantian waktu dan tempat yang terukur.

\section{KONSEP DAN HASIL PERANCANGAN}

Konsep pesan yang ingin disampaikan webtoon ini adalah memberikan informasi dan edukasi kepada pembaca agar dapat mengerti dan memahami namun tidak menghilangkan ketertarikannya terhadap Budaya Palang Pintu itu sendiri. Secara konseptual webtoon ini akan diberi judul "Dibalik Angan".

Konsep Kreatif yang dipakai adalah dengan merancang webtoon mengenai dan berunsur Budaya Palang Pintu dengan mengambil pendekatan genre slice of life dan romance. Dengan menggunakan kedua genre tersebut, pembaca bisa lebih merasa dekat dengan cerita dan karakter karena lebih manusiawi. Selain itu slice of life akan digunakan sebagai pengembangan karakter pada cerita.

Judul "Dibalik Angan" memiliki makna yang terikat dengan cerita dari webtoon ini sendiri, yaitu menceritakan kisah dan kejadian sebelum karakter utama memiliki mimpi atau angan untuk membesarkan sanggar palang pintu pemberian orang tuanya. "Angan" disini dipakai menggantikan kata seperti, mimpi, ambisi, tujuan, dan keinginan, yang bertujuan agar lebih menarik dan cocok untuk dijadikan judul (title bait).

Webtoon ini memiliki 4 karakter utama yaitu, Hassan Makmur, Enu Balya, Triani Alawiyah, dan Nala. Karakter pertama adalah Hassan Makmur, merupakan 
karakter utama yang diwariskan sanggar palang pintu oleh orang tuanya, ia menyukai Triani. Kedua Enu Balya, sahabat dari Hassan, yang setia menemani dirinya bahkan membantu mengurus sanggar. Triani Alawiyah adalah karakter ketiga berjenis kelamin perempuan yang dekat dengan Hassan, kemudian yang terakhir adalah Nala, seorang perempuan yang dikenal Hassan pada saat dijalan pulang, dan merupakan pacarnya diakhir cerita.

Salah satu kendala dalam perancangan cerita ini adalah menentukan alur intrik dan cerita romansa, meski begitu penulis berusaha membuatnya dengan mengacu kebeberapa referensi acak pada webtoon yang sudah tayang kemudian mengkombinasikan cerita-ceritanya.

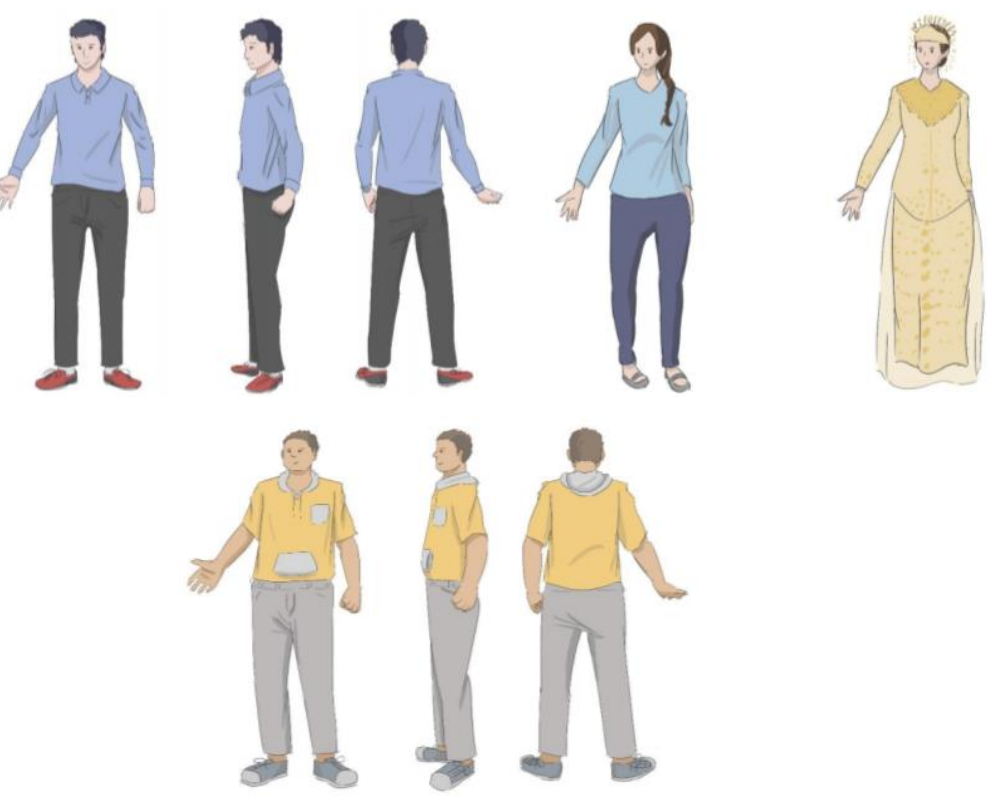

Gambar 2. Desain Karakter Dibalik Angan

(Sumber: Triadi \& Rahman, 2017)

Konsep media dari perancangan cerita yang berjudul "Dibalik Angan" ini akan disajikan dalam bentuk webtoon dengan episode berjumlah tiga episode, dan memiliki total halaman per episode adalah 54 halaman ditambah satu buah 
epilogue. Secara visualisasi, konsep yang diangkat akan berfokus pada empat karakter dengan masing-masing identitas visual dan perannya. Kemudian untuk memberi pembeda cerita ini akan dibuatkan sebuah logotype yang bertuliskan “Dibalik Angan” dengan garis miring warna merah diantara kedua kata tersebut.

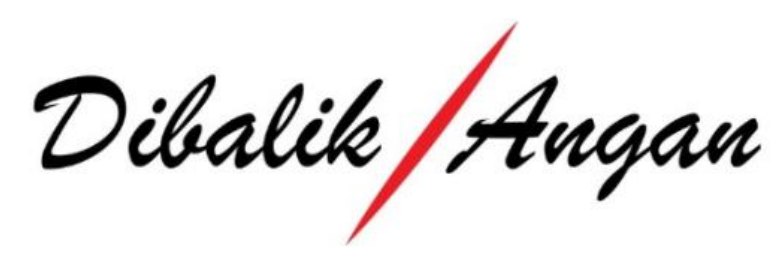

Gambar 3. Logotype Dibalik Angan

(Sumber: Triadi \& Rahman, 2017)

Jenis font yang digunakan adalah Brush Script MT dengan maksud mewakili genre slice of life dan romance yang terkesan lembut dan penuh kenangan. Warna hitam pada judul digunakan untuk merepresentasikan tulisan tangan sehingga lebih membuat cerita terasa membumi. Untuk garis miring warna merah bertujuan untuk mewakili suatu cerita yang krusial dan memiliki poin yang menentukan dalam memilih keputusan pada saat sebelum "Angan" itu tercipta.

Tipografi dalam balon kata dan sound effect akan menggunakan jenis font Anime Ace 2.0 BB dan Razing Reguler dengan ukuran huruf yang disesuaikan dengan mempertimbangkan keterbacaan dan unsur visual. Warna yang digunakan pada webtoon ini secara keseluruhan menggunakan warna-warna lembut dengan tujuan agar tidak memberatkan pembaca. Desain isi menggunakan grid system yang bervariasi. Hal ini untuk menghindari kemonotonan dan kejenuhan dengan tata letak yang sederhana (Pertiwi, 2016). 

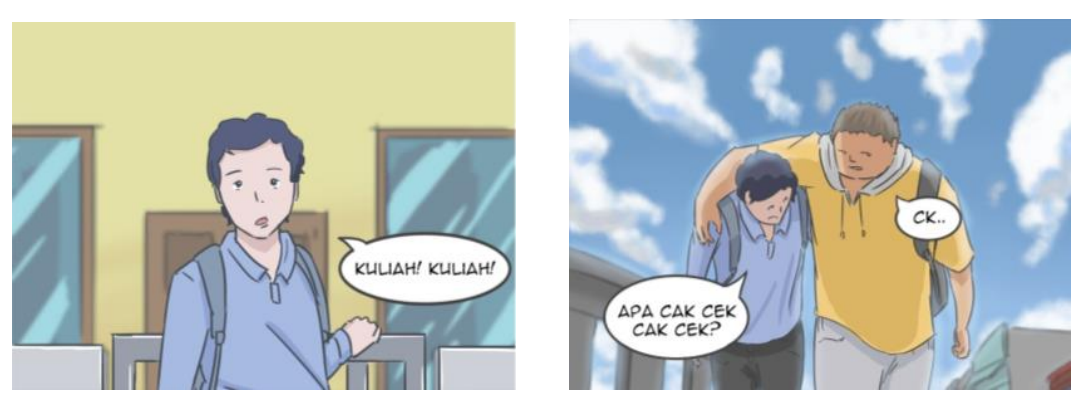

Gambar 4. Warna pada panel

(Sumber: Triadi \& Rahman, 2017)

Proses perancangan diawali dengan membuat empat storyline untuk setiap episode. Episode pertama akan memperkenalkan karakter utama yaitu Hassan Makmur dan sahabatnya Enu Balya. Episode ini juga akan memperkenalkan karakter Triani Alawiyah yang dekat dengan Hassan. Informasi dan edukasi dasar mengenai Palang Pintu dimunculkan disini. Episode dua akan menceritakan keluh kesah Hassan menghadapi kenyataan Ani, wanita yang disukainya akan menikah. Namun Hassan mendapat masalah mengenai Sanggar Makmur miliknya. Tak sadar, Hassan menerima pesanan untuk tampil di acara pernikahan Ani.

Pada episode tiga, Hassan, Enu, dan anggota sanggar lainnya menampilkan Palang Pintu di acara pernikahan Ani. Hassan dan Enu beradu silat dengan akhir Hassan kalah. Setelah kejadian tersebut, Hassan bertekad untuk membesarkan Sanggar Makmur dengan begitu sanggarnya bisa lebih banyak memberikan berkah terhadap orang lain. Pada episode terakhir, lima tahun sudah berlalu, Ani sudah memiliki anak perempuan. Suatu waktu Ani mengunjungi Sanggar Makmur yang sudah besar bersama anak perempuannya. Tak disangka, Hassan dan Nala pun sudah menjalin hubungan dan bersama mengurus sanggar tersebut.

Setelah storyline, proses perancangan berlanjut ke storyboard guna mempermudah pengerjaan karena sudah berbentuk sketsa kasar sehingga bisa dijadikan acuan dalam mengerjakannya. Lalu dilanjutkan dengan pengerjaan sketsa dan paneling, lineart, serta coloring. 


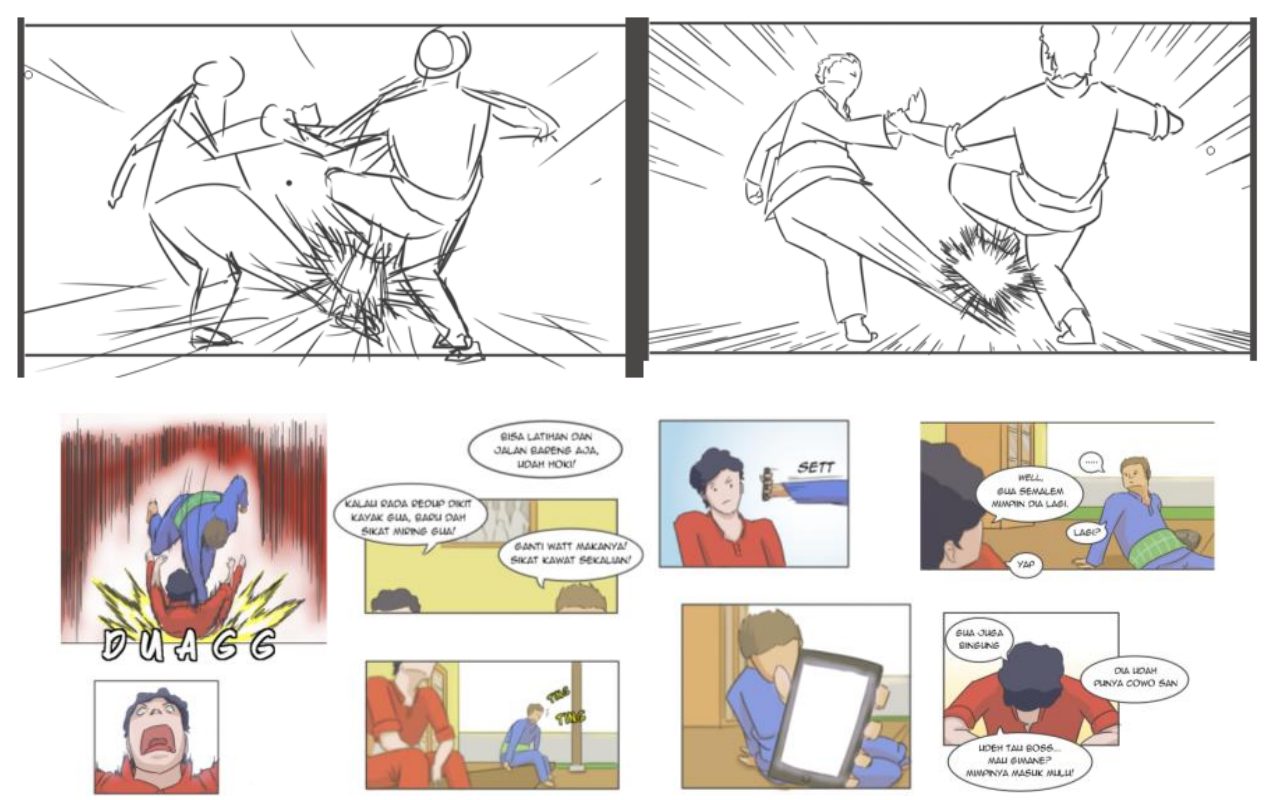

Gambar 5. Story board dan Panel-panel webtoon Dibalik Angan

(Sumber: Triadi \& Rahman, 2017)

Hasil akhir perancangan webtoon ini akan diunggah ke webtoon LINE sebagai webtoon challenge yang akan diatur waktu penayangannya tiap episode, sehingga bisa disimak secara berkala oleh target khalayak yang dituju.

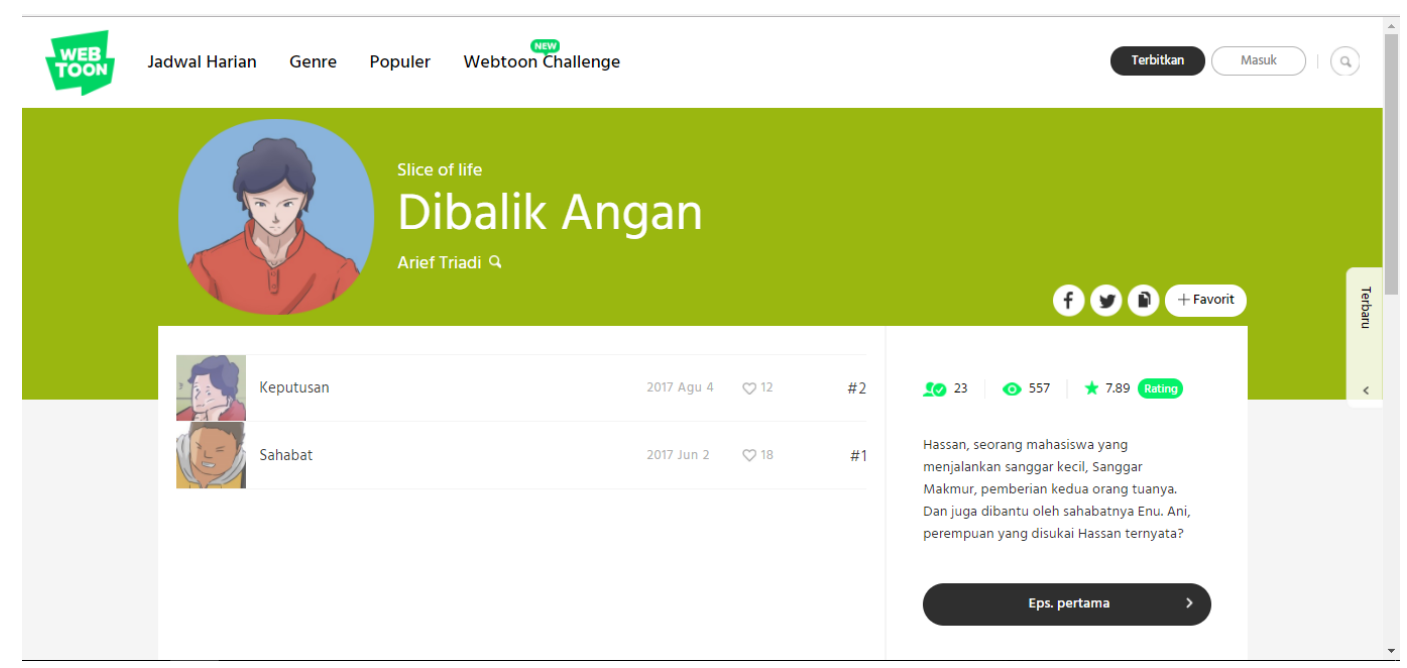

Gambar 6. Dibalik Angan setelah diunggah ke platform webtoon LINE

(Sumber: Triadi \& Rahman, 2017) 


\section{KESIMPULAN}

Berdasarkan hasil penelitian yang dilakukan, dengan menggunakan webtoon Budaya Palang Pintu ini dapat diakses, dipelajari dan dikenal oleh lebih banyak orang, terutama target khalayak yang dituju dengan cara menarik dan skala yang lebih luas. Penggunaan webtoon yang sering diakses oleh jutaan pembaca membuat penyebaran informasi berupa komik digital ini lebih mudah disebar. Pembelajaran melalui penceritaan visual berupa webtoon ini juga diusahakan dapat membuat pembaca lebih tertarik terhadap materi dan akan dapat menjadi media yang sesuai untuk memberikan informasi dan edukasi mengenai Palang Pintu. Kekuatan webtoon yang dapat diakses dengan mudah melalui teknologi yang kerap digunakan oleh target khalayak juga dapat memperluas aspek sosialisasi dan publikasi mengenai Budaya Palang Pintu sehingga bisa turut berkontribusi dalam melestarikan salah satu budaya di Nusantara ini. Selanjutnya untuk bisa lebih memperkuat dan memperluas efek pelestarian budaya ini, semoga penelitan-penelitian selanjutnya dapat mendalami dari segi keterlibatan atau interaksi dengan audies mengenai Budaya Palang Pintu ini.

\section{DAFTAR PUSTAKA}

Cho, Heekyoung. 2016. The Webtoon: A New Form for Graphic Narrative. The Comics Journal. Dilihat 18 Februari 2017. <http://www.tcj.com/the-webtoona-new-form-for-graphic-narrative>.

McCloud, Scott. 2001. Understanding Comics. Jakarta: Kepustakaan Populer Gramedia.

McCloud, Scott. 2006. Making Comics: Storytelling Secrets of Comics, Manga, and Graphic Novels. New York: HarperCollins.

Pertiwi, Gagat Ekasakti; Dwija P, I Dewa Alit; Soewardikoen, Didit Widiatmoko. 2016. Komik Edukasi Jajanan Sehat. Desain Komunikasi Visual, Manajemen Desain dan Periklanan (Demandia), 82-95. 
Statista. 2018. Number of registered LINE app users in selected countries. Diakses pada 27 Februari 2017. <https://www.statista.com/statistics/250927/ number-of-registered-line-app-users-in-selected-countries/>.

Steinberg, Marc. 2012. Anime's Media Mix: Franchising Toys and Characters in Japan. London: University of Minnesota Press.

Zpalanzani, Alvanov. Ahmad, Hafiz. dan Maulana, Beni. 2006. Mari Kita Bahas Komik, Histeria! Komikita: Membedah Komikita Masa Lalu, Sekarang dan Masa Depan. Jakarta: Elex Media Komputindo. 